\title{
Improved Electrochemical Performance of Ni-rich Cathode Materials via Al Gradient Doping
}

\author{
Mao-Huang Liu, ${ }^{1, *}$, Chien-Wen Jen ${ }^{1}$, Jin-Ming Chen ${ }^{2}$,Shih-Chieh Liao ${ }^{2}$ \\ ${ }^{1}$ Department of Chemistry, Fu Jen Catholic University, New Taipei City, Taiwan 24205 \\ ${ }^{2}$ Material and Chemical Research Laboratories, Industrial Technology Research Institute, HsinChu, \\ Taiwan 31040 \\ *E-Mail: 061355@mail.fju.edu.tw
}

doi: $10.20964 / 2018.05 .62$

Received: 9 January 2018 / Accepted: 6 March 2018 / Published: 10 April 2018

\begin{abstract}
An $\mathrm{Al}$ gradient-doped $\mathrm{LiNi}_{0.80} \mathrm{Co}_{0.19} \mathrm{Mg}_{0.01} \mathrm{O}_{2}(\mathrm{Al}(\mathrm{GD})$-LNCMgO) cathode was prepared via chemical co-precipitation followed by calcination. The average doping concentration of $\mathrm{Al}$ in the $\mathrm{Al}(\mathrm{GD})$ $\mathrm{LNCMgO}$ was $\sim 2 \mathrm{~mol} . \%$ with $\sim 7 \mathrm{~mol} . \%$ on the particle surface. $\mathrm{Al}(\mathrm{GD})$-LNCMgO returned values for initial efficiency, rate capability, cycle-life, thermal stability, and air-exposed stability that were superior to those of $\mathrm{Al}$ and $\mathrm{Mg}$ co-doped $\mathrm{LiNi}_{0.78} \mathrm{Co}_{0.19} \mathrm{Mg}_{0.01} \mathrm{Al}_{0.02} \mathrm{O}_{2}$ ( $\mathrm{LNCMgAlO}$ ), $\mathrm{LiNi}_{0.80} \mathrm{Co}_{0.19} \mathrm{Mg}_{0.01} \mathrm{O}_{2}$ ( $\mathrm{LNCMgO}$ ), and $\mathrm{LiNi}_{0.81} \mathrm{Co}_{0.19} \mathrm{O}_{2}$ (LNCO). The $\mathrm{Mg}$ substitution and Al-rich surface of $\mathrm{Al}(\mathrm{GD})-\mathrm{LNCMgO}$ suppressed the reactions of electrolytes with the material and inhibited increases in resistance. Doping $\mathrm{Mg}$ and $\mathrm{Al}$ in LNCO can also accelerate Li-ion diffusion.
\end{abstract}

Keywords: lithium ion battery, cathode material, $\mathrm{Mg}$ doped, $\mathrm{Al}$ gradient-doped, electrochemical performance..

\section{FULL TEXT}

(C) 2018 The Authors. Published by ESG (www.electrochemsci.org). This article is an open access article distributed under the terms and conditions of the Creative Commons Attribution license (http://creativecommons.org/licenses/by/4.0/). 